\title{
Numerical Analysis of Fatty Acid Profiles in the Identification of Staphylococci
}

\author{
By A. G. O’DONNELL $, 1,2 * \dagger$ M. R. NAHAIE, ${ }^{2}$ M. GOODFELLOW ${ }^{2}$ \\ D. E. MINNIKIN ${ }^{1}$ AND V. HÁJEK ${ }^{3}$ \\ Departments of Organic Chemistry ${ }^{1}$ and Microbiology ${ }^{2}$, The University, \\ Newcastle upon Tyne, UK \\ ${ }^{3}$ Department of Microbiology, School of Medicine, Palacky University, Olomouc, Czechoslovakia
}

(Received 28 January 1985)

\begin{abstract}
Representative strains of coagulase-positive and coagulase-negative staphylococci were degraded by acid methanolysis and the resultant fatty acid methyl esters analysed by gas chromatography. The quantitative data obtained were examined by cluster analysis. The coagulase-positive strains formed six major and one single-member cluster at the $90 \% S$-level. The Staphylococcus intermedius aggregate cluster included the single-member cluster and major clusters 1 and 2 . The four remaining clusters contained $S$. aureus strains and were homogeneous and distinct. The coagulase-negative strains were recovered in ten major and three singlemember clusters at the $90 \% S$-level. Five of the ten major clusters were reasonably homogeneous with respect to the existing classification. Thus, three $S$. capitis strains and five of the six $S$. epidermidis strains, two of the three $S$. hominis strains and five of the six $S$. simulans strains were recovered in separate clusters. Cluster 7 was divided into two subclusters; one contained five of the six $S$. hyicus strains and the other contained the two representatives of $S$. lentus. The remaining clusters were heterogeneous with regard to the named strains they contained.
\end{abstract}

\section{INTRODUCTION}

The genus Staphylococcus forms a distinct taxon (Kloos, 1980; Goodfellow, 1985) that encompasses strains which show extensive genetic diversity due to random mutation (Goodfellow et al., 1980). The genus has undergone marked revision since the last edition of Bergey's Manual of Determinative Bacteriology (Baird-Parker, 1974) and 20 species are now recognized primarily on the basis of chemical, biochemical, molecular, genetical, physiological and numerical phenetic data (Kloos, 1980; Kloos \& Schleifer, 1981; Goodfellow, 1985). A number of tests and procedures have been recommended for the identification of staphylococcal species (Kloos \& Schleifer, 1975; Kloos \& Wolfshohl, 1982; Brun et al., 1978; Feltham \& Sneath, 1982; Doern et al., 1983), but improved diagnostic methods are needed for the recognition of both species and biotypes.

Lipid analyses are being increasingly applied in bacterial systematics (see Goodfellow \& Minnikin, 1985) and have already provided some data of value for the classification and identification of staphylococci. Thus, staphylococci all have similar polar lipid patterns that can be used to separate them from other aerobic, Gram-positive cocci, and there is evidence that the variation in menaquinone profiles may be of value in the subgeneric classifications of these organisms (Nahaie et al., 1984). Some initial fatty acid analyses were mainly designed to distinguish staphylococci from micrococci (Ishizuka et al., 1966; Tornabene et al., 1970; Morrison et al., 1971; Jantzen et al., 1974) but these, together with other preliminary studies (Macfarlane, 1962; Rédai et al., 1967; White \& Frerman, 1968; Egge et al., 1971; Komaratat \& Kates, 1975; Kushwaha \& Kates, 1976), showed that the fatty acids of $S$. aureus and $S$.

† Present address: Department of Soil Science, The University, Newcastle upon Tyne NE1 7RU, UK. 
epidermidis consisted of major amounts of straight chain and methyl branched chain, saturated fatty acids of between 12 and 22 carbons. These early findings were confirmed and extended in a comprehensive survey (Durham \& Kloos, 1978) which showed that the fatty acid profiles of representative staphylococci were qualitatively similar, though no attempt was made to analyse the data quantitatively.

Most groupings of bacteria derived from fatty acid data have been based on visual interpretations of profiles though, in a few instances, numerical taxonomic techniques have been used (Drucker, 1981; Bousfield et al., 1983). Similarity values have been obtained using variations of the correlation coefficient, measures of the angular separation between two vectors in a multidimensional space, the degree of overlap between superimposed traces, and by measures of the Euclidean distance between paired objects (O'Donnell, 1985). Cluster analysis, where applicable, has used the average linkage method (Sokal \& Michener, 1958). Jantzen et al. (1974) were unable to distinguish between $S$. aureus and $S$. epidermidis when they used algorithms derived from the correlation coefficient and logarithmic transformation of their original fatty acid data.

In the present paper, representatives of species of Staphylococcus, including strains from recent chemical and numerical phenetic surveys (Goodfellow et al., 1983; Nahaie et al., 1984), were examined to see whether numerical analysis of fatty acid profiles was of value for the identification of coagulase-positive and coagulase-negative staphylococci.

\section{METHODS}

Organisms. The test strains (Tables 1-3) were maintained on nutrient agar (Oxoid) supplemented with glucose $(2 \%, w / v)$, and as frozen glycerol suspensions at $-25^{\circ} \mathrm{C}$ (Wellington \& Williams, 1979). Further details on some of the histories of the strains can be found elsewhere (Goodfellow et al., 1983; Nahaie et al., 1984).

Growth conditions. The coagulase-negative strains, which included $S$. hyicus, were grown overnight in $2 \mathrm{ml}$ Trypticase Soy Broth supplemented with glucose $(0.25 \%$, w/v; TSB; Difco). Aliquots $(0.05 \mathrm{ml})$ of each starter culture were then inoculated into conical flasks $(250 \mathrm{ml})$ containing $50 \mathrm{ml} \mathrm{TSB}$ and shaken at 200 r.p.m. at $35^{\circ} \mathrm{C}$. When the optical density (OD) reached 2.5 at $\mathrm{OD}_{600}$ or 3.5 at $\mathrm{OD}_{450}, 6 \mathrm{ml}$ of each culture was used to inoculate $300 \mathrm{ml}$ TSB in a 1 litre flask. This gave about $10^{8}$ c.f.u. per $50 \mathrm{ml}$. Inoculated flasks were then shaken in an orbital incubator $\left(150\right.$ r.p.m.) at $35^{\circ} \mathrm{C}$ for $24 \mathrm{~h}$. The cultures were checked for purity, killed by the addition of $1 \mathrm{ml}$ formalin $(40 \%, \mathrm{v} / \mathrm{v})$, harvested by centrifugation at $3000 \mathrm{~g}$ for $20 \mathrm{~min}$, washed twice with $67 \mathrm{~mm}$-Sorenson buffer at $\mathrm{pH} 7.0$ and freeze-dried. The $S$. aureus and $S$. intermedius strains were grown on sheep blood agar $(5 \%, \mathrm{v} / \mathrm{v})$ at $37^{\circ} \mathrm{C}$ for $24 \mathrm{~h}$ followed by $2 \mathrm{~d}$ at ambient temperature. Harvested biomass was washed twice with normal saline and freeze-dried.

Extraction and analysis of fatty acids. Dried biomass $(50 \mathrm{mg})$ was degraded using the whole-organism acid methanolysis procedure of Minnikin et al. (1980). Analytical and preparative thin-layer chromatography (TLC) was done as previously described (O'Donnell et al., 1982). Gas chromatography (GC) of the purified fatty acid methyl esters was done using a polar $6 \mathrm{~m}$ Silar $10 \mathrm{C}$ column run isothermally at $195^{\circ} \mathrm{C}$, and representative samples were also analysed at $230^{\circ} \mathrm{C}$ on a non-polar $6 \mathrm{~m}$ OV-l column (O'Donnell et al., 1982). Retention times and peak areas were recorded automatically with a Shimadzu CE1B computing integrator. The identity of individual esters was established by comparison with the retention times of standard mixtures and by their behaviour on both OV-1 and Silar $10 \mathrm{C}$ columns.

Numerical analysis of fatty acid data. To remove the effects of sample size, all data were standardized before numerical analysis. For each chromatogram, the Shimadzu CE1B computing integrator divided each peak area by the total peak area and multiplied by 100 (Tables 2 and 3). To make data input easier, standardized values were multiplied by 10. Data were analysed by the cluster analysis routine (Sneath \& Sokal, 1973) from the GENSTAT (Alvey et al., 1977) statistical package. Similarities were calculated by the generalized similarity coefficient of Gower (1971) and clustered by the complete linkage (furthest neighbour) algorithm. Since different media were used to obtain the biomass the data on the coagulase-positive (Table 2) and coagulase-negative strains (Table 3) were analysed separately.

\section{RESULTS}

TLC of whole-organism methanolysates of the test strains showed the presence of predominant spots $\left(R_{F} 0 \cdot 8\right)$ corresponding to non-hydroxylated fatty acid methyl esters (Minnikin et al., 1980). The results of the GC analyses of the non-hydroxylated long chain 
Table 1. Designation and source of coagulase-positive strains

\author{
Laboratory \\ SCH no. \\ Strain designation and source* \\ $103 \dagger \quad$ Staphylococcus aureus NCTC 8532; isolated from human pleural fluid \\ 113-114 S. aureus biotype A; V. Hájek, Microbiological Institute, Palachý University, Olomouc, \\ Czechoslovakia, B13, B31; patients with bronchopneumonia complicating influenza infection \\ $116-118$ \\ $119-121$ \\ $S$. aureus biotype B; V. Hájek, V1, V5, V15; slaughtered pigs \\ $122-124$ \\ $125-127$ \\ $128-130$ \\ $131-133$ \\ $134-136$ \\ 137-139 \\ $140 \dagger-142$ \\ S. aureus biotype B; V. Hájek, S26, S41, S49; chickens with septicaemia \\ $S$. aureus biotype C; V. Hájek, M1, M39, M85; cows with mastitis \\ $S$. aureus biotype C; V. Hájek, R18, R28, R31; sheep \\ $S$. aureus biotype D; V. Hájek, Z10, Z17, Z20; hares \\ Staphylococcus intermedius biotype E; V. Hájek, P13, P15, P71; dogs \\ $S$. intermedius biotype E; V. Hájek, K2, K20, K35; horses \\ $S$. intermedius biotype E; V. Hájek, L91, L103, L105; minks \\ $S$. intermedius biotype F; V. Hájek, H11, H12, H17; pigeons \\ * Biotypes recognized by Hájek \& Marsalek (1971, 1976). \\ † Type strain.
}

components are shown in Tables 2 and 3 . All of the test strains produced iso, anteiso and straight chain fatty acids; unsaturated fatty acids being absent in all cases. Values recorded as trace amounts were scored as zero for the numerical analysis. Since $S$. aureus 103 (Table 2) was grown on the same medium as the coagulase-negative strains, it was excluded from the quantitative studies.

The results of the quantitative analyses of the fatty acid data from the coagulase-positive strains (Table 2) is shown in Fig. 1 . It can be seen that the $S$. aureus and $S$. intermedius strains formed two aggregate clusters defined at the $73 \%$ similarity $(S)$ level. The sharp segregation of these two species at the $51 \% S$-level was not surprising as the constituent strains showed substantial quantitative variations in fatty acid profiles, especially in the relative amounts of 13-methyltetradecanoic acid (iso-15), 12-methyltetradecanoic acid (anteiso-15), 14-methylhexadecanoic acid (iso-17) and octadecanoic acid (18:0).

The coagulase-positive strains fell into six major and one single-member cluster, $S$. intermedius 133 , defined at the $90 \% S$-level. The $S$. intermedius aggregate cluster encompassed the single-member cluster and major clusters 1 and 2 . The four remaining clusters, all of which contained $S$. aureus strains, were also homogeneous and distinct. It was also interesting that all the $S$. intermedius isolates from horses fell into cluster 1 , and those from mink and pigeons into cluster 3. Similarly, all the $S$. aureus strains from cattle and swine fell into cluster 4 .

In the corresponding analysis, the coagulase-negative strains were recovered in ten major and three single-member clusters at the $90 \% S$-level (Fig. 2). The three $S$. capitis strains fell into cluster 1, five of the six strains labelled $S$. epidermidis (Goodfellow et al., 1983) into cluster 5, two of the three $S$. hominis strains into cluster 6 , and five of the six $S$. simulans strains into the homogeneous and well-defined cluster 10 . However, the type strain of $S$. simulans formed a single-member cluster attached to cluster 10 , and the remaining $S$. epidermidis, $S$. cohnii and $S$. hominis strains were recovered in clusters 1,2 and 3 , respectively. Cluster 7 was divided into two subclusters; one contained five of the six $S$. hyicus strains and the other contained the two representatives of $S$. lentus. The type strain of $S$. sciuri formed a single-member cluster attached to cluster 7 . Similarly, the type strains of $S$. hyicus subsp. chromogenes fused with cluster 7, albeit at a much lower level of similarity than the $S$. sciuri strain. In contrast, clusters $2,3,4,8$ and 9 were markedly heterogeneous with respect to the named strains they contained.

\title{
DISCUSSION
}

The detection of straight chain and methyl branched iso and anteiso fatty acids of between 12 and 22 carbons in all of the test strains is in good agreement with the results of previous studies based on various growth media and conditions (Macfarlane, 1962; Ishizuka et al., 1966; Rédai et 


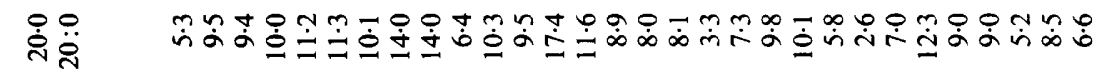

$\dot{9} \dot{0}$

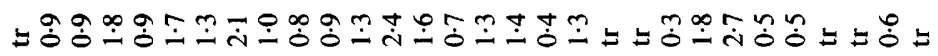

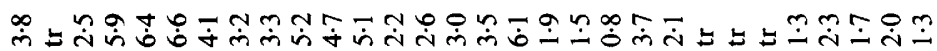

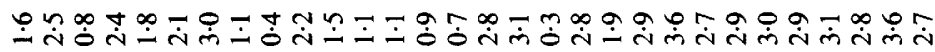

$\stackrel{\varphi}{\oplus} \underset{\infty}{\mathscr{\infty}}$

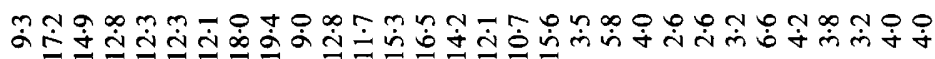

$\stackrel{+\infty}{ \pm} \stackrel{\infty}{2}$

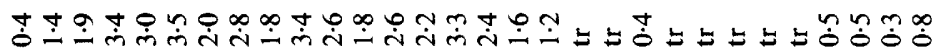

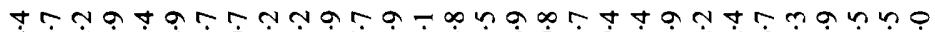

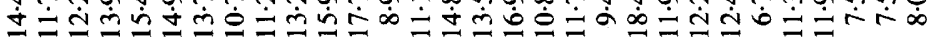

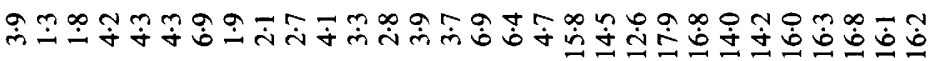





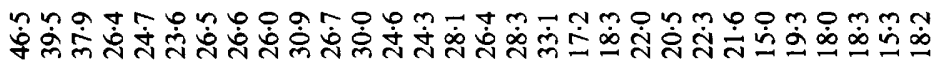



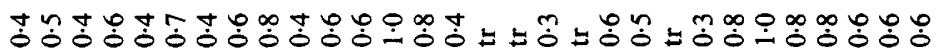
$\stackrel{+}{\dot{\Xi}} \dot{\square}$

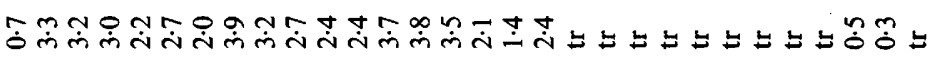






Fig. 1. A dendrogram showing the relationships between Staphylococcus aureus and $S$. intermedius strains based on the analysis of fatty acid methyl ester composition using Gower's coefficient $\left(S_{\mathrm{G}}\right)$ and complete linkage cluster analysis; ${ }^{*}$, type strain.

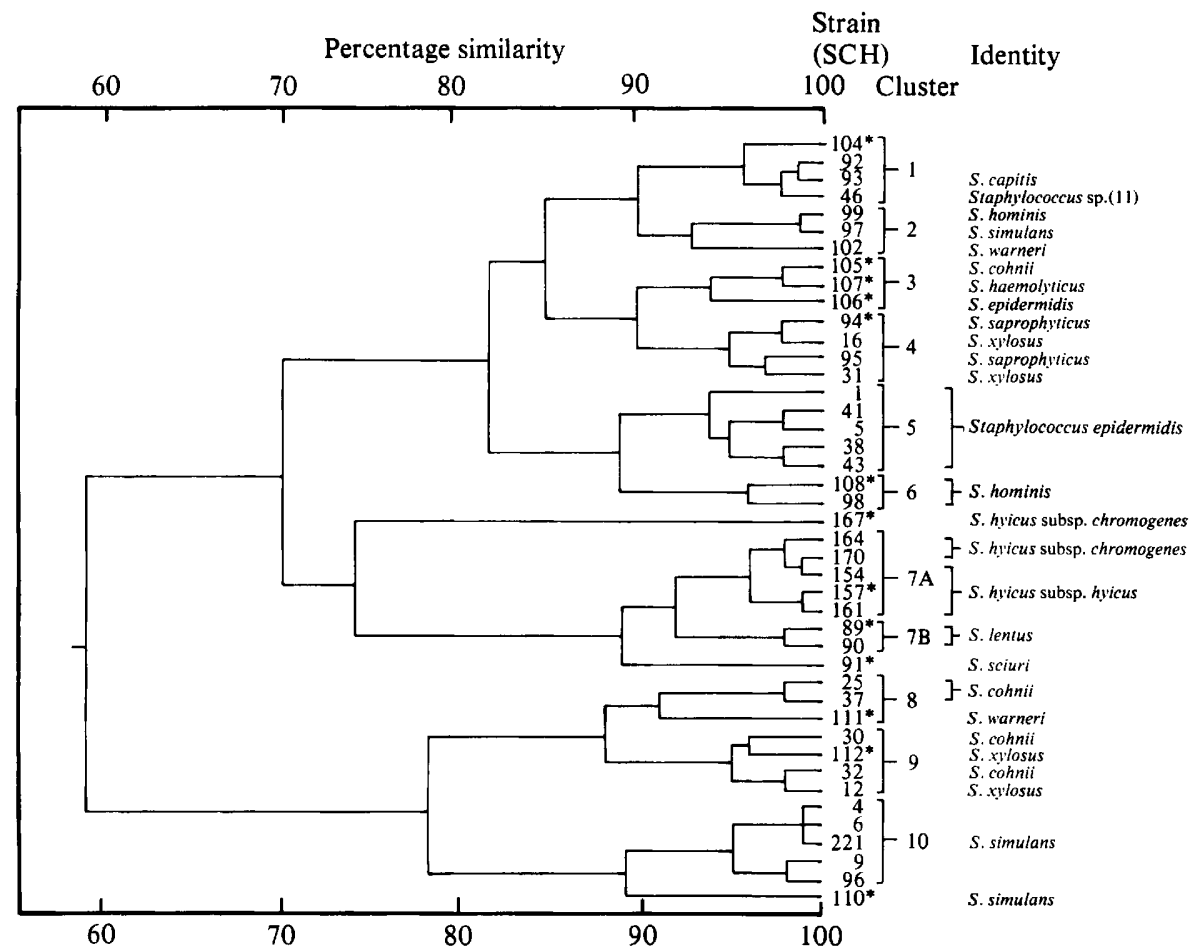

Fig. 2. A dendrogram showing the relationships between representatives of some coagulase-negative species of Staphylococcus based on the analysis of fatty acid methyl ester composition using Gower's coefficient $\left(S_{\mathrm{G}}\right)$ and complete linkage cluster analysis; ${ }^{*}$, type strain. 


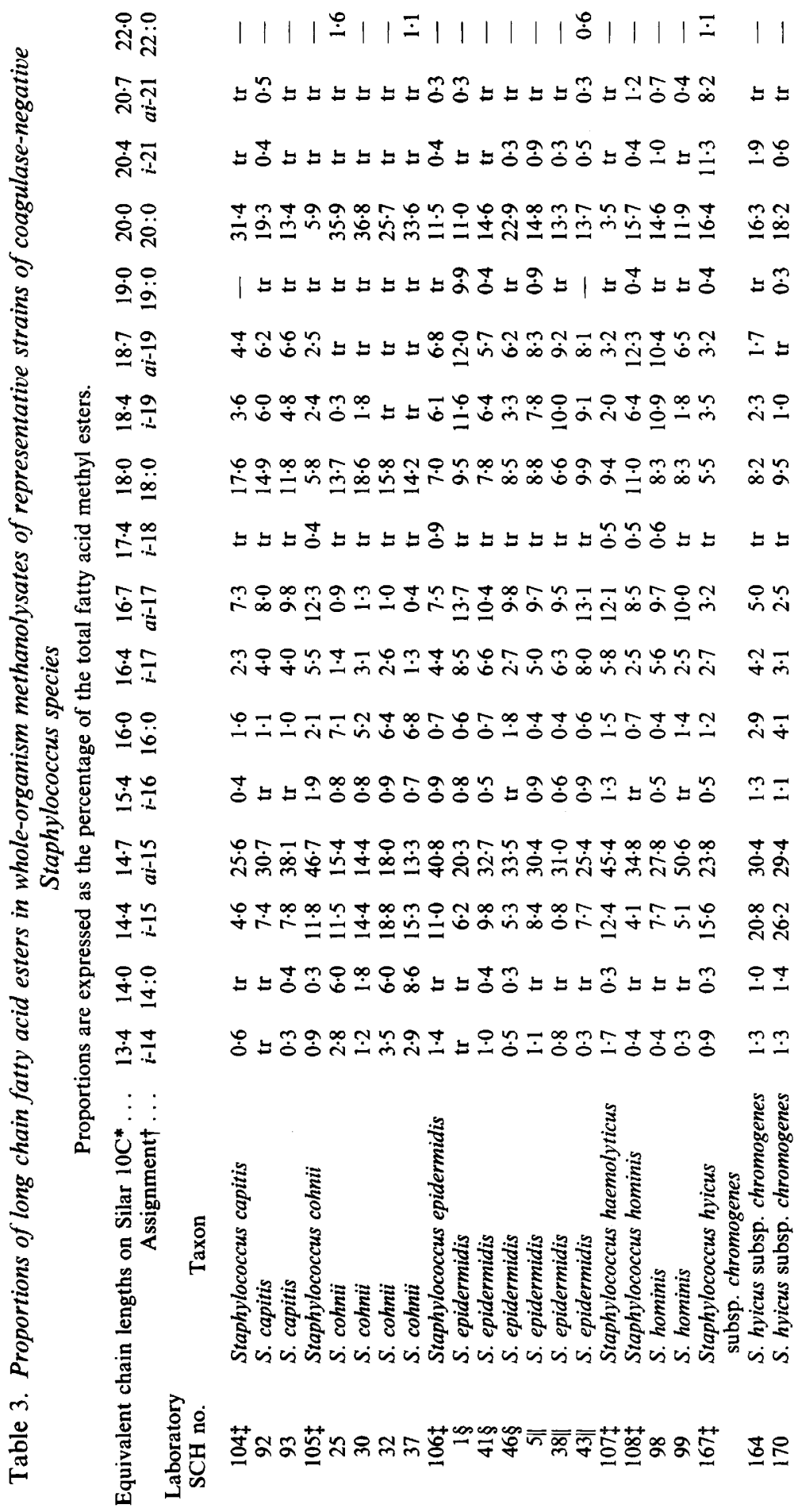









al., 1967; White \& Frerman, 1968; Tornabene et al., 1970; Egge et al., 1971; Morrison et al., 1971 ; Komaratat \& Kates, 1975; Kushwaha \& Kates, 1976 ; Durham \& Kloos, 1978; Sincoweay et al., 1981). The results of the present study are, however, at variance with the observation (Durham \& Kloos, 1978) that a straight chain $C_{22}$ component was diagnostic for strains of $S$. warneri. Indeed, the present data and those of Sincoweay et al. (1981) show that this component is not restricted to $S$. warneri; it is also present in $S$. cohnii, $S$. epidermidis, $S$. haemolyticus, $S$. hominis, $S$. saprophyticus, $S$. simulans and $S$. hyicus subsp. hyicus.

Given the qualitative differences in the fatty acid composition of the $S$. aureus and $S$. intermedius strains, it was not surprising that the representatives of the two species were sharply separated in the numerical analysis of the fatty acid data. Both the $S$. aureus and $S$. intermedius strains exhibited high mean intraspecific similarities but an interspecific value of only $51 \%$. These fatty acid data provide yet further evidence for assigning coagulase-positive staphylococci to the two currently recognized species. The integrity of $S$. aureus and $S$. intermedius is also supported by biochemical data (Schleifer et al., 1976), DNA homology data (Meyer \& Schleifer, 1978) and numerical phenetic data (Hájek \& Schindler, 1981; Goodfellow et al., 1983), and by wall composition (Schleifer \& Kandler, 1972; Hájek, 1976; Schleifer et al., 1976) and isoprenoid quinone composition (Nahaie et al., 1984). Although requiring more detailed study, the fact that some coagulase-positive strains clustered into host-specific varieties suggests that for some taxa a numerical analysis of fatty acid data may provide useful epidemiological or ecological information. Host-specific varieties of $S$. aureus have previously been recognized in numerical phenetic analyses of physiological criteria (Szulga et al., 1976). The quantitative differences found between the fatty acid components of the present and earlier taxonomic studies on $S$. aureus (Durham \& Kloos, 1978; Sincoweay et al., 1981) may be attributed to differences in cultivation conditions (Váczi et al., 1967; Rédai et al., 1969, 1971, 1972).

The overall similarities in the fatty acid profiles of the coagulase-negative strains made it necessary to use an objective quantitative analysis to evaluate the data. Even so, only four of the ten major clusters defined at the $90 \% S$-level could be equated with the phena obtained in the numerical phenetic survey of Goodfellow et al. (1983). Cluster 1 corresponded to $S$. capitis, cluster 5 to a phenon containing strains labelled $S$. epidermidis, cluster 6 to $S$. hominis and cluster 10 to $S$. simulans. In addition, clusters $7 \mathrm{~A}$ and $7 \mathrm{~B}$ were equated with $S$. hyicus and $S$. lentus, respectively. The recovery of $S$. sciuri as a single-member cluster separate from $S$. lentus supports the view that these taxa merit species status (Schleifer et al., 1983). However, the marked lack of congruence between the fatty acid and numerical phenetic data with respect to clusters $2,3,4,8$ and 9 requires explanation, especially since relatively good congruence has been found between the numerical phenetic classification (Goodfellow et al., 1983) and results from studies on DNA homology (Gladek et al., 1985) and wall composition (Schumacher-Perdreau et al., 1983).

Sincoweay et al. (1981) also obtained heterogeneous taxa when the quantitative fatty acid profiles of 61 coagulase-negative staphylococci from bovine milk and 19 reference strains of established staphylococcal species were analysed numerically. The first of two aggregate groups contained strains of $S$. hyicus and $S$. lentus and the second $S$. cohnii, $S$. epidermidis, $S$. haemolyticus, $S$. hominis, $S$. saprophyticus and $S$. warneri. Each of the two aggregate taxa also contained strains of $S$. capitis, $S$. simulans and $S$. xylosus. Given that the identity of the test strains is correct, the lack of congruence between the results of Sincoweay et al. (1981) and those of the present study may be due to the selection of strains from the periphery of clusters (see later discussion) or in the numerical methods used. The latter has been shown to have a pronounced effect on cluster analysis of fatty acid data (Bøe \& Gjerde, 1980).

It is possible that the lack of congruence between the numerical phenetic and fatty acid data is because the variation in fatty acid composition amongst coagulase-negative staphylococci is not high enough to be useful as a species determinant. A similar conclusion was reached by Jantzen et al. (1974) with respect to staphylococci. Alternatively, it is possible that the phenetic classification of coagulase-negative taxa is one in which some of the species are separated in taxonomic hyperspace by very short distances so that the situation approximates more closely to a spectrum of forms than to clearly defined species. In a situation such as this the selection of test strains becomes very important as representatives taken towards the periphery of a species are 
more likely to result in cluster overlap than those nearer to the cluster centre. In the present instance this situation seems unlikely as cluster 3 contained three organisms, the type strains of $S$. cohnii, $S$. epidermidis and $S$. haemolyticus, which have been sharply distinguished in DNA pairing studies (Schleifer et al., 1979; Goodfellow et al., 1980).

The lack of congruence between the numerical phenetic and fatty acid data highlights an important problem in bacterial systematics that is likely to occur more frequently as a multiplicity of analytical and statistical procedures are applied in bacterial classification and identification. Thus, given two incompatible or partially compatible classifications, what criteria can be used to decide which, if any, of the taxonomic structures is most appropriate? The application of powerful taxonomic techniques such as nucleic acid pairing may complicate matters further by yielding additional incongruities. In such instances the search for alternative taxonomic markers is unlikely to resolve the situation fully. It seems more likely that detailed work on strain selection, on the taxonomic significance of particular tests or characters, and the development of suitable statistical procedures capable of interlocking classifications from different sources will provide a sound base for future studies (Sneath, 1985).

\section{REFERENCES}

Alvey, W. G., Banfield, C. F., Baxter, R. I., Gower, J. C., Krzanowski, W. J., Lane, P. W., Leech, P. K., Welder, J. A., Payne, R. W., Phelps, K. M., Rogers, C. E., Ross, G. J. S., Simpson, H. R., Todd, A. D., Wedderburn, R. W. M. \& WilkiNSON, G. N. (1977). GENSTAT Reference Manual. Harpenden, UK: Rothamsted Experimental Station.

Baird-Parker, A. C. (1974). Staphylococcus. In Bergey's Manual of Determinative Bacteriology, 8th edn, pp. 483-489. Edited by R. E. Buchanan and N. E. Gibbons. Baltimore: Williams \& Wilkins.

BøE, B. \& GJERde, J. (1980). Fatty acid patterns in the classification of some representatives of the families Enterobacteriaceae and Vibrionaceae. Journal of General Microbiology 116, 41-49.

Bousfield, I. J., Smith, G. L., Dando, T. R. \& HobBs, G. (1983). Numerical analysis of total fatty acid profiles in the identification of coryneform, nocardioform and some other bacteria. Journal of General Microbiology 129, 375-394.

Brun, Y., Fleurette, J. \& Forey, F. (1978). Micromethod for biochemical identification of coagulase-negative staphylococci. Journal of Clinical Microbiology 8, 503-508.

Doern, G. V., Earls, J. E., Jeznach, P. A. \& Parker, D. S. (1983). Species identification and biotyping by the API STAPH IDENT system. Journal of Clinical Microbiology 17, 260-263.

DRUCKER, D. B. (1981). Microbiological Applications of Gas-Chromatography. Cambridge: University Press.

Durham, D. R. \& Kloos, W. E. (1978). Comparative study of the total cellular fatty acids of Staphylococcus species of human origin. International Journal of Systematic Bacteriology 28, 223-228.

Egge, H., Murawski, U., Chatranon, W. \& ZilliKEN, F. (1971). Die verzweigten Fettsauren von Straphylococcus aureus, eine gaschromatographischmassenspektrometriche Analyse. Zeitschrift für Naturforschung 26b, 893-901.

Feltham, R. K. A. \& Sneath, P. H. A. (1982). Construction of matrices for computer-assisted identification of aerobic Gram-positive cocci. Journal of General Microbiology 128, 713-720.

Gladek, A., TKacz, A., Zakrzewska, J., MoRDARSKI, M., Goodfellow, M. \& Pulverer, G. (1985). Characterisation of xylose positive staphylococci by DNA-DNA reassociation. Zentralblatt für Bakteriologie und Hygiene (Abteilung I, Supplement) (in the Press).

GoODFElLow, M. (1985). Staphylococcal systematics: past, present and future. Zentralblatt für Bakteriologie und Hygiene (Abteilung I, Supplement) (in the Press).

GoOdFEllow, M. \& MinNikin, D. E. (1985). Introduction to chemosystematics. In Chemical Methods in Bacterial Systematics, pp. 1-15. Edited by $\mathbf{M}$. Goodfellow \& D. E. Minnikin. London \& New York: Academic Press.

Goodfellow, M., Mordarski, M., TKacz, A., Szyba, K. \& Pulverer, G. (1980). Polynucleotide sequence divergence among some coagulase-negative staphylococci. Zentralblatt für Bakteriologie, Parasitenkunde, Infektionskrankheiten und Hygiene (Abteilung I, Originale A) 246, 10-22.

Goodfellow, M., Alderson, G., Nahaie, M. R., Peters, G., Schumacher-Perdeau, F., Pulverer, G., HeczKo, P. B. \& Mordarski, M. (1983). Numerical taxonomy of Staphylococcus. Zentralblatt für Bakteriologie, Parasitenkunde, Infektionskrankheiten und Hygiene (Series A) 256, 7-24.

GowER, J. C. (1971). A general coefficient of similarity and some of its properties. Biometrics 27, $857-874$.

HÁJEK, V. (1976). Staphylococcus intermedius, a new species isolated from animals. International Journal of Systematic Bacteriology 26, 401-408.

HÁJEK, V. \& MARSALEK, E. (1971). The differentiation of pathogenic staphylococci and a suggestion for their taxonomic classification. Zentralblatt für Bakteriologie, Parasitenkunde, Infektionskrankheiten und Hygiene (Abteilung I, Originale A) 217, 176182.

HÁJEK, V. \& MARSALEK, E. (1976). Evaluation of classificatory criteria for staphylococci. Zentralblatt für Bakteriologie, Parasitenkunde, Infektionskrankheiten und Hygiene (Abteilung I, Supplement 5), 1121. 
HÁJEK, V. \& SChindler, J. (1981). Cluster analysis of coagulase-positive staphylococci. Zentralblatt für Bakteriologie, Mikrobiologie und Hygiene (Abteilung I, Supplement 10), 27-35.

Ishizuka, I., Ueta, N. \& Yamakawa, T. (1966). Gas chromatographic studies of microbial components. II. Carbohydrate and fatty acid constitution of the family Micrococcaceae. Japanese Journal of Experimental Medicine 36, 73-83.

Jantzen, E., Bergan, T. \& Bøvre, K. (1974). Gas chromatography of bacterial whole cell methanolysates. VI. Fatty acid composition of strains within Micrococcaceae. Acta pathologica et microbiologica scandinavica 82B, 785-798.

KLoos, W. E. (1980). Natural populations of the genus Staphylococcus. Annual Review of Microbiology 34, 559-592.

Kloos, W. E. \& Schleifer, K. H. (1975). Simplified scheme for routine identification of human Staphylococcus species. Journal of Clinical Microbiology 1, 8287.

Kloos, W. E. \& Schleifer, K. H. (1981). The genus Staphylococcus. In The Prokaryotes: a Handbook of Habitats, Isolation and Identification of Bacteria, vol. 2, pp. 1548-1589. Edited by M. P. Starr, H. Stolp, H. G. Trüper, A. Balows \& H. G. Schlegel. Berlin: Springer-Verlag.

KLoos, W. E. \& WolfSHOHL, J. S. (1982). Identification of Staphylococcus species with the API STAPHIDENT. Journal of Clinical Microbiology 16, 509516.

Komaratat, P. \& Kates, M. (1975). The lipid composition of a halotolerant species of Staphylococcus epidermidis. Biochimica et biophysica acta 398 , 464-484.

KushwaHA, S. C. \& Kates, M. (1976). Nonpolar lipids of a halotolerant species of Staphylococcus epidermidis. Canadian Journal of Biochemistry 54, 79-85.

Macfarlane, M. G. (1962). Lipid components of Staphylococcus aureus and Salmonella typhimurium. Biochemical Journal 82, 40P-41P.

MeYeR, S. A. \& SchleIFER K. H. (1978). Deoxyribonucleic acid reassociation in the classification of coagulase-positive staphylococci. Archives of Microbiology 117, 183-188.

Minnikin, D. E., Hutchinson, I. G., Caldicott, A. B., GoODFELlow, M. (1980). Thin-layer chromatography of methanolysates of mycolic acid containing bacteria. Journal of Chromatography 188, 221-233.

Miwa, T. K., Mikolajczak, K. L., Earle, F. R. \& WolfF, I. A. (1960). Gas chromatographic characterization of fatty acids. Analytical Chemistry 32, 1739-1742.

Morrison, S. J., Tornabene, T. G. \& Kloos, W. E. (1971). Neutral lipids in the study of the relationships of members of the family Micrococcaceae. Journal of Bacteriology 108, 353-358.

NaHaie, M. R., Goodfellow, M., Minnikin, D. E. \& HÁJEK, V. (1984). Polar lipid and isoprenoid quinone composition in the classification of Staphylococcus. Journal of General Microbiology 130, 2427-2437.

O'DonNell, A. G. (1985). Numerical analysis of chemotaxonomic data. In Computer Assisted Bacterial Systematics pp. 403-414. Edited by M. Goodfellow, D. Jones \& F. G. Priest. London \& New York: Academic Press.
O'Donnell, A. G., Goodfellow, M. \& Minnikin, D. E. (1982). Lipids in the classification of Nocardioides: reclassification of Arthrobacter simplex (Jensen) Lochhead in the genus Nocardioides (Prauser) emend. O'Donnell et al. as Nocardioides simplex comb. nov. Archives of Microbiology 133, 323-329.

RÉDAI, I., RÉTHY, A. \& VÁCZI, L. (1967). Fatty acid composition of Staphylococcus aureus strains differing in antibiotic sensitivity. Acta microbiologica Academiae scientiarum hungaricae 14, 77-82.

RédAI, I., Réthy, A. \& Rozgonyi, F. (1969). Fatty acids in Staphylococcus aureus and Escherichia coli cultured in vivo. Acta microbiologica Academiae scientiarum hungaricae 16, 219-225.

RédaI, I., RÉthy, A., SEbessi-GönCzy, P. \& VáCzI, L. (1971). Lipids in Staphylococcus aureus and Escherichia coli cultured in the presence of human serum. Acta microbiologica Academiae scientiarum hungaricae 18, 297-306.

Rédai, I., Sebessi-Gönczy, P. \& Váczi, L. (1972). Effect of chloramphenicol on phospholipid synthesis in sensitive Staphylococcus aureus strains. Acta microbiologica Academiae scientiarum hungaricae 19, 187-193.

Schleifer, K. H. \& Kandler, O. (1972). Peptidoglycan types of bacterial cell walls and their taxonomic implications. Bacteriological Reviews 36, 407-477.

SCHLEIFER, K. H., Schumacher-Perdreau, F., GötZ, F., POPP, B. \& HÁJEK, V. (1976). Chemical and biochemical studies for the differentiation of coagulase-positive staphylococci. Archives of Microbiology 110, 263-270.

SCHLEIFER, K. H., MEYER, S. A. \& RUPPRECHT, M. (1979). Relatedness among coagulase-negative staphylococci: deoxyribonucleic acid reassociation and comparative immunological studies. Archives of Microbiology 122, 93-101.

SCHLEIFER, K. H., GeYeR, U., KilPPER-Balz, R. \& DEVRIES, L. A. (1983). Elevation of Staphylococcus sciuri subsp. lentus (Kloos et al.) to species status: Staphylococcus lentus (Kloos et al.) comb. nov. Systematic and Applied Microbiology 4, 382-387.

Schumacher-Perdreau, F., Rotering, H. \& PulVERER, G. (1983). Cell wall analysis and taxonomy of staphylococci. Zentralblatt für Bakteriologie, Parasitenkunde, Infektionskrankheiten und Hygiene (Series A) 256, 25-38.

Sincoweay, H., Miyagawa, E. \& Kume, T. (1981). Cellular fatty acid composition in staphylococci isolated from bovine milk. National Institute of Animal Health Quarterly (Japan) 21, 14-20.

SNEATH, P. H. A. (1985). Future of numerical taxonomy. In Computer Assisted Bacterial Systematics, pp. 415-431. Edited by M. Goodfellow, D. Jones \& F. G. Priest. London \& New York: Academic Press.

SNEATH, P. H. A. \& SoKal, R. R. (1973). Numerical Taxonomy: The Principles and Practice of Numerical Classification. San Francisco: W. H. Freeman \& Co.

SOKAL, R. R. \& MiCHENER, C. D. (1958). A statistical method for evaluating systematic relationships. University of Kansas Science Bulletin 38, 1409 1438.

Szulga, T., Meyer, W., Witte, W. \& Horn, G. (1976). Numerical taxonomy of Staphylococcus aureus. Zentralblatt für Bakteriologie (Abteilung I, Supplement 5), 101-104. 
Tornabene, T. G., Morrison, S. J. \& Kloos, W. E. (1970). Aliphatic hydrocarbon contents of various members of the family Micrococcaceae. Lipids $\mathbf{5}$, 929-937.

VÁCZI, L., RÉdAI, I. \& Réthy, A. (1967). Changes in fatty acid composition under various cultural conditions. Acta microbiologica Academiae scientiarum hungaricae 14, 293-298.
Wellington, E. M. H. \& Williams, S. T. (1979). Preservation of actinomycete inoculum in frozen glycerol. Microbios Letters 6, 151-157.

White, D. C. \& Frerman, F. E. (1968). Fatty acid composition of the complex lipids of Staphylococcus aureus during formation of the membrane bound electron transport system. Journal of Bacteriology 95 , 2198-2209. 